\title{
Learning to read: developing processes for recognizing, understanding and pronouncing written words
}

\author{
Morag Stuart* \\ Institute of Education, University of London, UK
}

Major theories of how skilled readers recognize, understand and pronounce written words include processes for phonological recoding (i.e., translating segments of print to their corresponding segments of sound) and processes by which direct access is achieved from printed words to their meanings. If these are the processes employed in skilled reading, then these are the processes which children learning to read must develop in order to become skilled readers. This paper reviews experimental findings relevant to the development of both sets of processes in beginning and early readers.

\section{Introduction}

It is a truth universally acknowledged that reading is much more than deciphering the words on the page-yet decipher the words we must, if we are to make any sense of the text. Elsewhere in this issue you will find a paper by Nation and Angell reviewing what is known about how children develop the complex abilities necessary for making sense of written texts, and a paper by Coltheart presenting a model of the cognitive processes by which skilled readers recognize, understand and pronounce written words. The present paper presents evidence relevant to understanding how children develop their ability to read the words on the page. The focus here, as elsewhere in this issue, is on children's learning, but clearly the ways in which children are known to learn have implications for the ways in which they might best be taught. Children enter school differentially equipped for the task of learning to read, and learn at different rates and with varying degrees of success.

\footnotetext{
*School of Psychology and Human Development, Institute of Education, 25 Woburn Square, London WC1H 0AA, UK. Email: m.stuart@ioe.ac.uk
} 
Understanding the developmental trajectory of that idealized and illusory creature, the 'normally developing' reader, allows teachers to assess where the children they teach are currently situated along the developmental path to skilled reading, what they have already learned and understood, and what they should next experience and/or be taught.

\section{Theoretical framework: skilled word reading}

The framework adopted here will be that of the dual route model (see Coltheart et al., 2001; Jackson \& Coltheart, 2001). A clear account of this is given in the paper by Coltheart in this issue. According to the model, skilled readers have two sets of processes available for reading. Non-lexical processes involve recoding the graphemes of printed words into their corresponding phonemes using an internalized set of grapheme-phoneme correspondence rules. Lexical processes store orthographic, semantic and phonological representations of words and procedures for transferring information across these three levels. ${ }^{1}$ A simplified diagram of this model is presented in Figure 1. The left-hand side of Figure 1 delineates lexical processes,

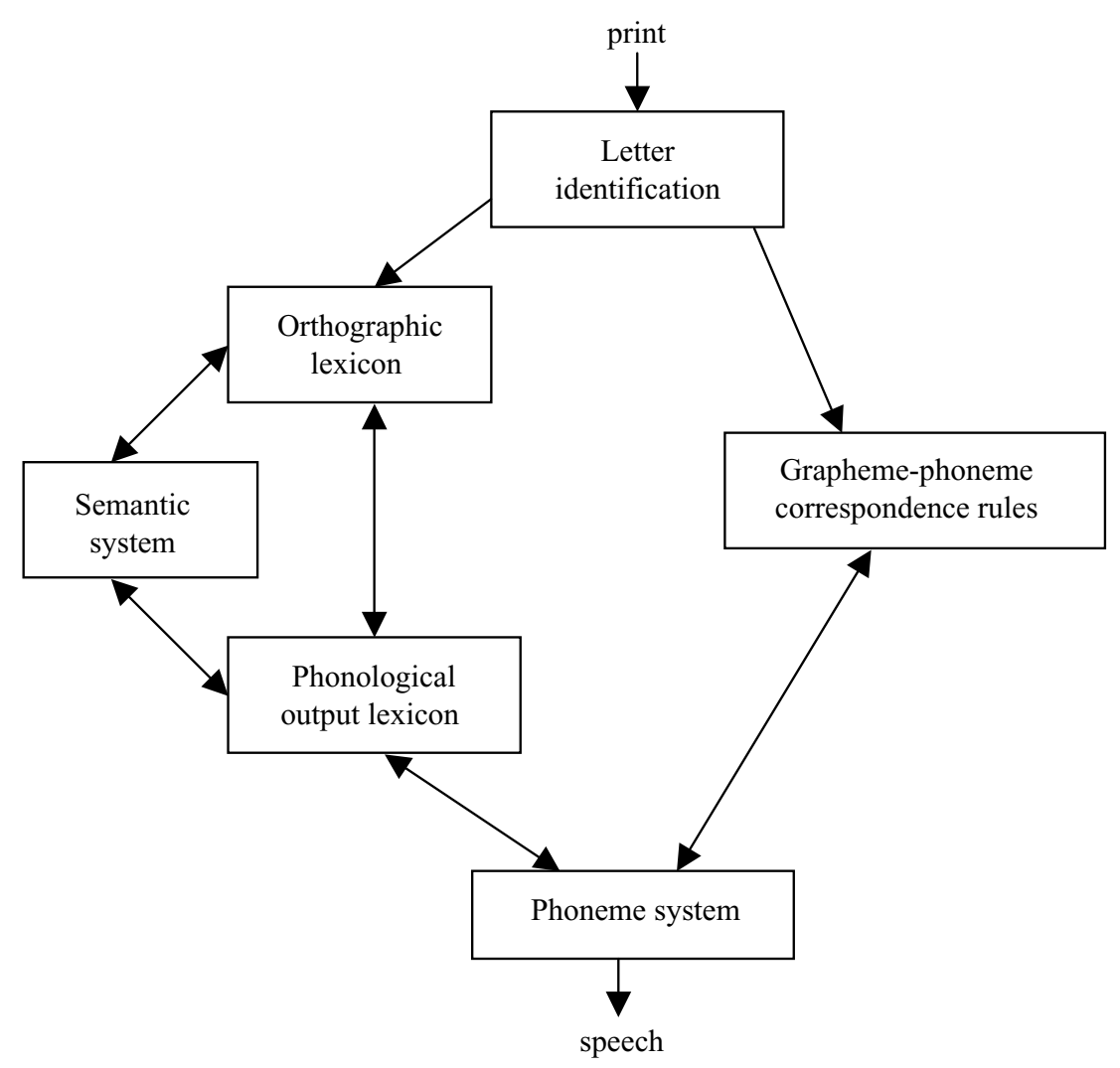

Figure 1. The dual route theory of reading aloud 
processes at the word level. The right-hand side delineates non-lexical processes, processes at sub-word level. Both sets of processes rely on the initial identification of letters in the printed word.

\section{Identifying letters}

As shown in Figure 1, in reading, first the letters in each word encountered in a written text activate representations of letters stored in the reader's mind (see Figure 1, 'Letter identification'). How do children set up these representations of letters? Current knowledge of children's letter learning is presented later under the heading 'The importance of letter knowledge'. Letters identified then start activation simultaneously in both lexical and non-lexical processing routes. Each sequence of activation is described in turn below.

\section{Non-lexical processing}

Letters of the word currently attended to are parsed into their component graphemes (e.g., catch $\rightarrow$ c ... a ... tch). These graphemes are converted to phonemes (e.g., c ... a ... tch $\rightarrow / \mathrm{k} / \ldots / \mathfrak{x} / . . . / c$ ) (see Figure 1, 'Grapheme-phoneme correspondence rules') and the phonemes are assembled into a pronunciation (e.g., $/ \mathrm{k} / \ldots / \mathfrak{x} / \ldots /$ ç/ $\rightarrow / \mathrm{k} æ c ̧ /)$. At this point, the word can be pronounced, and its representation in the phonological output lexicon is activated. The activated phonological form of the word in turn activates the word's meaning in the semantic system. At this point, the word is understood. Evidence relevant to how children establish grapheme-phoneme correspondence rules and assembly procedures is presented later under the heading 'Setting up non-lexical processes'.

\section{Lexical processing}

Meanwhile, in the lexical route, the representation of the spelling pattern of the word currently attended to is activated (see Figure 1, 'Orthographic lexicon'. The orthographic lexicon can be conceived of as a dictionary containing spelling patterns for all the printed words known to a reader). At this point, the word is recognized. Words activated in the orthographic lexicon access their meanings stored in the reader's mind (see Figure 1, 'Semantic system'). At this point, the word is understood. Word meanings activated in the semantic system access the phonological representation of that word's meaning (see Figure 1, 'Phonological output lexicon'). At this point, the word can be pronounced. It is important to bear in mind that the semantic system and the phonological output lexicon subserve both oral and written language. Thus reading, even at the single word level, is heavily dependent on oral language. Evidence relevant to how children establish orthographic representations and link these to their meanings is presented later under the heading 'Setting up lexical processes'. 


\section{The development of word reading skills}

We turn now to a consideration of what is known about how children develop lexical and non-lexical processes, under the headings indicated in the previous section.

\section{The importance of letter knowledge}

Studies of children's knowledge of letter names and letter sounds typically find that children learn letter names earlier than letter sounds (Mason, 1980; Treiman et al., 1996; McBride-Chang, 1999), although those 5-year-olds who know more letter names also know more letter sounds (Stuart, 1986). Children's letter name knowledge on school entry is also one of the best predictors of reading at the end of the first year at school (see Bond \& Dykstra, 1967; Tunmer et al., 1988). Various speculative explanations of this relationship have been advanced: letter name knowledge might simply reflect the child's preschool and home background (Share et al., 1983); or might be an index of the child's phonological memory (Share, 1995); or it might tap the child's familiarity with letter shapes (Ehri, 1986).

There is still, within the educational world, controversy as to whether or not it is confusing for children to be taught both the names and sounds of letters. Those who believe it is confusing often advocate that letter sounds should be taught first, as these are of more direct use in reading. However, the research literature suggests that knowledge of letter names facilitates the learning of letter sounds. For example, Treiman et al. (1998) showed that children were quicker to learn the sounds for letters whose names they already knew than the sounds for letters whose names they did not know. Furthermore, letter sounds were learned more easily if they comprised the initial sound of the letter name (e.g., $\mathrm{B}-/ \mathrm{b} /, \mathrm{T}-/ \mathrm{t} /$ ) than if they comprised the final sound of the letter name (e.g., F - /f/; S - /s/). Share (2004a) suggested that children's ability to identify phonemes in words might underlie this: young children find it easier to identify the initial than the final phoneme in words (Stanovich et al., 1984). It would therefore seem sensible to teach both names and sounds of letters. Names may be easier to learn because, being syllables rather than phonemes, they are more perceptible, and also because children expect things to have names and are accustomed to rapidly acquiring the names of things.

\section{Setting up non-lexical processes}

Findings that children most easily learn the sound of a letter where this is the first sound of the letter name (i.e., learn / $/$ / for $T$ more easily than $/ \mathrm{r} /$ for $\mathrm{R}$ ) emphasize the importance of phoneme awareness to learning the correspondences between letters and their sounds. To deduce that the letter $\mathrm{T}$ has the sound $/ \mathrm{t} /$ requires that the child can segment the letter name into its component phonemes $/ \mathrm{t} / \mathrm{i} /$, and that the child assumes that the first phoneme is the sound for that letter. There is evidence that children do make these deductions and assumptions, from a sample of children learning to read in the early 1980s, when direct teaching of letter 
sounds was given a very low priority in the schools this sample attended (Stuart, 1986). If children were shown printed letters and asked to give the sound for each letter, many children gave /d/ as the sound for the letter W (doubleyoo), $/ \mathrm{W} /$ as the sound for the letter $\mathrm{Y}(/ \mathrm{waI} /)$ and $/ \varepsilon /$ as the sound for the letters $\mathrm{F}, \mathrm{L}, \mathrm{M}, \mathrm{N}$ and $\mathrm{S}$ $(/ \varepsilon f /, / \varepsilon l /, / \varepsilon \mathrm{cm} /, / \varepsilon \mathrm{en} /$ and $/ \varepsilon \mathrm{s} /)$. It is clearly important that once children can identify the initial sounds of spoken words (e.g., tell you that 'cat' begins with $/ \mathrm{k} /$ ), they should be taught letter sounds, because their own deductions and assumptions produce the wrong sound for many letters.

Ability to identify the initial sounds of spoken words is one aspect of phonological awareness - of knowing that spoken words are patterns of sound as well as signifiers of meaning. There is a wealth of literature demonstrating that phonological awareness, and especially phoneme awareness, is a good predictor of word reading skills (see Nation \& Hulme, 1997; Muter et al., 1998; Hulme et al., 2002; Macmillan, 2000). There is also a wealth of literature showing that initial teaching which incorporates phoneme awareness training in conjunction with teaching graphemephoneme correspondence (GPC) rules accelerates the acquisition of word reading skills (see Byrne \& Fielding-Barnsley, 1989, 1991, 1993, 1995; Torgesen et al., 1992; Uhry \& Shepherd, 1993; Castle et al., 1994). Phonological training that does not include teaching of GPC rules improves phonological awareness, but not reading (see Hatcher et al., 1994).

An issue that is currently exercising many in the educational world is the optimal timing, nature and pace for 'phonics' teaching. When should children be taught phonics? What are the essential elements of effective phonics teaching? How quickly can children learn GPC rules and start to use these in their reading? The following evidence from my own research speaks to some of these issues. Stuart (1999) presents an intervention study carried out in five schools in one inner London LEA, prior to the introduction of the National Literacy Strategy. One hundred and twelve children in six Year $\mathrm{R}$ classes were given one hour per day literacy teaching for 12 weeks. In three classes, the teaching was based around use of 'big books', with teachers particularly asked to spend time on word level work, including letter sound relationships. In the other three classes, phoneme segmentation and blending skills and grapheme-phoneme correspondences were taught, using 'jolly phonics' and with strict adherence to that programme.

In relation to the issue of when children should be taught phonics (how early can this kind of teaching be profitably introduced?), immediately after the 12 week intervention, $95 \%$ of children in the 'jolly phonics' intervention could correctly indicate the printed letter that represented a given phoneme for more than half $(13+)$ of the letters of the alphabet, and $84 \%$ of them could recall the correct phoneme for more than 20 graphemes ('jolly phonics' teaches one grapheme for each phoneme in English, so children are immediately taught one writing pattern for each long vowel: e.g., ee for /i/ as in 'green' and 'mean', ai for/eI/ as in 'maid', 'made' and 'may', etc). The comparative figures for children in the 'big book' intervention were $63 \%$ and $58 \%$ respectively. Moreover, the mode (the most frequently occurring score) for letter sound recognition in the 'jolly phonics' group was 25 (on a test with 26 items) 
and for letter sound recall it was 21 (on a test with 42 items). Comparative figures here for the 'big book' group were 18 and 0 respectively. Thus it is clear that most of these 5-year-olds were ready and able to learn about letter sounds and graphemephoneme correspondences, provided these were taught in a systematic, structured and fun way.

In this intervention, we had two measures of phoneme segmentation: giving the sound at the beginning of a word, and segmenting a spoken word into all its component phonemes. From the immediate post-test data it is clear that 5-year-olds are ready and able to learn to identify initial phonemes: $91 \%$ of the 'jolly phonics' group and $60 \%$ of the 'big book' group were correct on more than half the items presented. The most commonly occurring score in the 'jolly phonics' group was 24 (on a test with 24 items) - but for the 'big book' group it was zero. Teaching method was clearly affecting performance here. The task of segmenting a spoken word into all its component phonemes was more difficult: only $35 \%$ of the 'jolly phonics' group and $4 \%$ of the 'big book' group were correct on more than $50 \%$ of the items in this test, and the most commonly occurring score in both groups was zero (on a test with 11 items). But again, the significantly better performance of the 'jolly phonics' group testifies to the importance of the teaching they received, which was of some benefit to many children. Five-year-olds, even those from the disadvantaged backgrounds of many of this sample, are not too young to be taught phoneme segmentation and phonics - and they can learn consonant and vowel digraphs too.

Stuart et al. (2003) report an extension of the 'one term of structured phonics teaching in Year R' model to a further 22 schools in the same LEA, 17 of which provided pre- and post-test data on a total of 365 5-year-olds taking part. Results from this extension project confirmed the findings reported above, that children of this age are ready for and able to benefit from structured phoneme awareness and phonics teaching.

In this study, phoneme blending skills were also assessed, with two measures taken. First, the children were shown a sheet of pictured objects and asked to point to the picture represented by a spoken sequence of segmented sounds (e.g., to point to the picture of a horse in response to the sequence $6 / \mathrm{h} / \ldots / \mathrm{o} / \ldots / \mathrm{s} /$ '). Second, the children were asked to produce a pronunciation from a spoken sequence of segmented sounds (e.g., to respond 'hill' to the sequence ' $/ \mathrm{h} / . . . / \mathrm{I} / \ldots / \mathrm{l} /$ '). The first test was easier than the second: on immediate post-test of the picture-point test, $5 \%$ of the children scored zero, and $60 \%$ were at ceiling; the mean score was 4.8 items correct, and the most commonly occurring score was six (on a test with six items). On the say-theword post-test, $30 \%$ of the children scored zero, and $30 \%$ were at ceiling; the mean score was three, with a most commonly occurring score of zero (again, on a six-item test). At immediate post-test, $57 \%$ of the sample was successful in reading one or more unfamiliar three-letter CVC words and $40 \%$ in reading one or more threeletter CVC non-words; $15 \%$ of the sample was already close to ceiling on the nonword reading test, scoring $8+/ 10$ items correct.

These data suggest that (a) 5-year-olds can profit from structured phonics teaching; (b) many of them can quickly absorb grapheme-phoneme correspondence 
rules; (c) very few children fail to make some progress; and (d) teaching phoneme blending skills in tandem with GPC rules enables many children immediately to begin to develop and use a rudimentary non-lexical processing system that allows them to work out the pronunciations of words and non-words.

With respect to the question of what the essential elements of effective phonics teaching might be, three things appear necessary: for reading, children must be taught GPC rules and how to blend phonemes into pronunciations; for spelling, they must be taught also to segment whole words into their component phonemes which can then be translated into graphemes. All these essential aspects of effective phonics teaching are included in the National Literacy Strategy Progression in Phonics materials.

\section{Setting up lexical processes}

There is a widely held view that children acquire new items of printed vocabulary very rapidly from their reading experience, or, in the terminology used here, children quickly set up orthographic representations of new words they encounter in printed texts (see Manis, 1985; Hogaboam \& Perfetti, 1978; Reitsma, 1983a, b, 1989; Ehri \& Saltmarsh, 1995; Share, 1999).

Whilst this may be true of children who have made a good start in learning to read, it does not appear to be true of absolute beginners. Stuart et al. (2000) present two studies of word learning in the first term of Year R. In the first study, children were asked to try to remember 16 target words from books they read with the experimenter. After 36 exposures to each target word, the mean number of words recognized out of context was 4.95 , range $0-12$. This poor rate of learning was checked against each child's learning within the classroom. In their first term at school, the children had encountered from 39 to 277 different words (mean 125.9) in the books they were reading in class and taking home to read. On average, only four words appeared more than 20 times in any child's vocabulary pool and, on average, children could read only one word (range $0-10$ ) from their vocabulary pool when words from this pool were presented out of context.

In the second study, learning new print vocabulary from text reading was contrasted with learning from flashcards. Children either experienced or were taught eight new printed words. Flashcard teaching proved much the more efficient method: children taught by flashcards learned on average seven of the eight words, in a total of seven minutes teaching time; children in the text reading condition learned on average three words in a total of 13 minutes of teaching.

The flashcard advantage for words presented out of context was replicated when children were asked to read each word in a sentence, and in a word to picture matching task. Thus, the children taught with flashcards not only found it easier to set up an orthographic representation of each word, but they also had made connections from that representation to the word's meaning (i.e., with reference to Figure 1, had made links from the orthographic lexicon to the semantic system). In the first study presented by Stuart et al. (2000), there was some sign of a semantic influence on the 
ease of setting up these links, with nouns more likely to be learned than function words (adverbs, prepositions, etc). The children clearly were engaged in lexical processing, as there was no difference in ease of learning regular words such as 'camel' (which can be read accurately by non-lexical processes) and irregular words such as 'onion' (which can't).

There is a growing consensus from recent research that phoneme awareness and knowledge of GPC rules influences the setting up of lexical as well as non-lexical processes. Stuart and Coltheart (1988) presented evidence that the kinds of errors children made during their first two years at school changed as their phonological awareness and ability to provide sounds of letters of the alphabet improved. The task was to read aloud words presented singly without any context. Children successful in both phonological tasks and letter sound knowledge were much more likely to make errors where the first and last letters of the target were retained (e.g., to misread 'back' as 'book', 'horse' as 'house', or 'tall' as 'till'). Such errors have subsequently been named 'scaffolding errors' (Savage et al., 2001) and the proportion of such errors made by 6-year-olds has been shown to predict their ability to read words accurately two years later. For those interested, Savage and Stuart (in press) present a theoretical rationale for why this should be so. In brief, these authors suggest that once children have formed a skeletal orthographic representation of a word, consisting of its initial and final consonant(s), repeated experience of reading the word in context allows the child to infer the correspondence between the medial grapheme and phoneme (i.e., to infer that the 'or' grapheme in 'horse' corresponds to the phoneme $/ \mathrm{J} /$ ).

Evidence that children can and do infer GPCs from their experience of reading words is provided by Stuart et al. (1999) and by Thompson et al. (1999). Repeated experience of reading words already skeletally represented also allows the child to fill in the missing detail of the internal parts of their orthographic representations so that these become fully specified letter-by-letter. A similar account of the development of orthographic representations is given by Ehri (1992). For further evidence that children with good phoneme awareness and good letter-sound knowledge set up more detailed orthographic representations of words more rapidly than those without such prerequisite skills, see Dixon et al. (2002).

Share (1995) presents a different view of the way in which non-lexical processes contribute to the establishment of orthographic representations. In this view, children's ability to 'sound out' unfamiliar words they encounter in their reading becomes a powerful self-teaching device, with words so decoded then entered immediately as new items in the orthographic lexicon (see Cunningham et al., 2002). However, Share (2004b), in a study of Grade 1 children (7-year-olds) in Israel who were learning to read Hebrew, found no evidence of self-teaching in these beginning readers. Share speculates that this may be because the pointed Hebrew script used by beginning readers is so transparent in terms of the regularity and consistency of GPC rules that they feel no need to set up orthographic representations: all reading necessary at this point in their careers can be successfully and rapidly achieved through non-lexical processes. Share (2004b) did find evidence supportive of the 
self-teaching hypothesis in Grade 3 readers, and suggests this is because during Grade 2 children typically experience a huge explosion in the number of vocabulary items to which they are exposed, as reading tuition shifts from 'learning to read' to 'reading to learn'.

\section{Conclusions}

Over the past quarter century, psychological research has made considerable progress towards delineating and understanding the ways in which children learn to read the words on the page. This is a crucial part of the process of learning to read, because once written words have been recognized and understood, their meanings are available to those parts of the child's language system that have been already established to understand and produce spoken language. Unfortunately, too little of this research is known to those responsible for teaching children to read, and the present paper is an attempt to redress this. Understanding what 'successful' children do should allow us to design teaching programmes that better ensure the successful progress of all children.

\section{Note}

1. It is worth noting here that the 'triangle' (connectionist) model (see Seidenberg \& McClelland, 1989; Plaut et al., 1996; Harm \& Seidenberg, 1999, 2004) also proposes two routes from print to sound, one direct and one via semantics. Unlike the dual route model, a single processing mechanism underlies all processing in the triangle model.

\section{Notes on contributor}

Morag Stuart taught KS1 children to read and write for over 13 years. She is Professor of the Psychology of Reading at the Institute of Education, University of London and is Editor of the Fournal of Research in Reading. Her research into early reading development asks how children come to be able to recognize, understand and pronounce written words.

\section{References}

Bond, G. K. \& Dykstra, R. (1967) The cooperative research program in first grade reading instruction, Reading Research Quarterly, 2, 5-142.

Byrne, B. \& Fielding-Barnsley, R. (1989) Phonemic awareness and letter knowledge in the child's acquisition of the alphabetic principle, Fournal of Educational Psychology, 81, 313-321.

Byrne, B. \& Fielding-Barnsley, R. (1991) Evaluation of a program to teach phonemic awareness to young children, fournal of Educational Psychology, 83, 451-455.

Byrne, B. \& Fielding-Barnsley, R. (1993) Evaluation of a program to teach phonemic awareness to young children: a 1-year follow-up, fournal of Educational Psychology, 85, 104-111.

Byrne, B. \& Fielding-Barnsley, R. (1995) Evaluation of a program to teach phonemic awareness to young children: a 2- and 3-year follow-up and a new preschool trial, fournal of Educational Psychology, 87, 488-503. 
Castle, J. M., Riach, J. \& Nicholson, T. (1994) Getting off to a better start in reading and spelling: the effects of phonemic awareness instruction within a whole language program, fournal of Educational Psychology, 86, 350-359.

Coltheart, M. (2006) Dual route and connectionist models of reading: an overview, London Review of Education, 4(1).

Coltheart, M., Rastle, K., Perry, C., Langdon, R. \& Ziegler, J. C. (2001) DRC: a dual route cascaded model of visual word recognition and reading aloud, Psychological Review, 108, 204-256.

Cunningham, A. E., Perry, K. E., Stanovich, K. E. \& Share, D. L. (2002) Orthographic learning during reading: examining the role of self-teaching, fournal of Experimental Child Psychology, 82, 185-199.

Dixon, M., Stuart, M. \& Masterson, J. (2002) The role of phonological awareness and the development of orthographic representations, Reading $\mathcal{E}$ Writing: An Interdisciplinary fournal, 15, 295-316.

Ehri, L. C. (1986) Sources of difficulty in learning to spell and read, Advances in Developmental \& Behavioral Pediatrics, 7, 121-195.

Ehri, L. C. (1992) Reconceptualizing the development of sight word reading and its relationship to recoding, in: P. B. Gough, L. C. Ehri \& R. Treiman (Eds) Reading acquisition (Hillsdale, NJ, Lawrence Erlbaum).

Ehri, L. C. \& Saltmarsh, J. (1995) Beginning readers outperform older disabled readers in learning to read words by sight, Reading and Writing, 7, 295-326.

Harm, M. W. \& Seidenberg, M. S. (1999) Phonology, reading acquisition, and dyslexia: insights from connectionist models, Psychological Review, 106, 491-528.

Harm, M. W. \& Seidenberg, M. S. (2004) Computing the meanings of words in reading: cooperative division of labor between visual and phonological processes, Psychological Review, 111, $662-720$.

Hogaboam, T. W. \& Perfetti, C. A. (1978) Reading skill and the role of verbal experience in decoding, fournal of Educational Psychology, 70, 701-729.

Hulme, C., Hatcher, P. J., Nation, K., Brown, A., Adams, J. \& Stuart, G. (2002) Phoneme awareness is a better predictor of early reading skill than onset-rime awareness, fournal of Experimental Child Psychology, 82, 2-28.

Jackson, N. E. \& Coltheart, M. (2001) Routes to reading success and failure (Hove, Psychology Press).

Macmillan, B. (2000) Rhyme and reading: a critical review of the research methodology, fournal of Research in Reading, 25, 4-39.

Manis, F. R. (1985) Acquisition of word identification skills in normal and disabled readers, Fournal of Educational Psychology, 77, 78-90.

Mason, J. M. (1980) When do children begin to read: an exploration of four year old children's letter and word reading competencies, Reading Research Quarterly, 15, 203-227.

McBride-Chang, C. (1999) The ABC's of the ABC: the development of letter-name and lettersound knowledge, Merrill-Palmer Quarterly, 45, 285-308.

Muter, V., Hulme, C., Snowling, M. \& Taylor, S. (1998) Segmentation, not rhyming, predicts early reading and spelling skills, Fournal of Experimental Child Psychology, 71, 3-27.

Nation, K. \& Angell, P. (2006) Learning to read and learning to comprehend, London Review of Education, 4(1).

Nation, K. \& Hulme, C. (1997) Phonemic segmentation, not onset-rime segmentation, predicts early reading and spelling skills, Reading Research Quarterly, 32, 154-167.

Plaut, D. C., McClelland, J. L., Seidenberg, M. S. \& Patterson, K. (1996) Understanding normal and impaired word reading: computational principles in quasi-regular domains, Psychological Review, 103, 56-115.

Reitsma, P. (1983a) Printed word learning in beginning readers, Fournal of Experimental Child Psychology, 36, 321-339.

Reitsma, P. (1983b) Word-specific knowledge in beginning reading, fournal of Research in Reading, 6(1), 41-56. 
Reitsma, P. (1989) Orthographic memory and learning to read, in: P. G. Aaron \& R. M. Joshi (Eds) Reading and writing disorders in different orthographic systems, (Dordrecht/Norwell, MA, Kluwer Academic).

Savage, R., Stuart, M. \& Hill, V. (2001) The role of scaffolding errors in reading development: evidence from a longitudinal and a correlational study, British fournal of Educational Psychology, 71, 1-13.

Savage, R. \& Stuart, M. (2006) A developmental model of reading acquisition based upon early scaffolding errors and subsequent vowel inferences, Educational Psychology, 26(1), 33-53.

Seidenberg, M. S. \& McClelland, J. L. (1989) A distributed, developmental model of word recognition and naming Psychological Review, 96, 523-568.

Share, D. L. (1995) Phonological recoding and self-teaching: sine qua non of reading acquisition, Cognition, 55, 151-218.

Share, D. L. (1999) Phonological recoding and orthographic learning: a direct test of the selfteaching hypothesis, Fournal of Experimental Child Psychology, 72, 95-129.

Share, D. L. (2004a) Knowing letter names and learning letter sounds: a causal connection, Fournal of Experimental Child Psychology, 88, 213-233.

Share, D. L. (2004b) Orthographic learning at a glance: on the time course and developmental onset of self-teaching, fournal of Experimental Child Psychology, 87, 267-298.

Share, D. L., Jorm, A. F., Maclean, R., Matthews, R. \& Waterman, B. (1983) Early reading achievement, oral language ability, and a child's home background, Australian Psychologist, 18, 75-89.

Stanovich, K. E., Cunningham, A. E. \& Cramer, B. B. (1984) Assessing phonological awareness in kindergarten children: issues of task comparability, fournal of Experimental Child Psychology, 38, 175-190.

Stuart, K. M. (1986) Phonological awareness, letter-sound knowledge and learning to read. Unpublished Ph.D. thesis, University of London.

Stuart, M. (1999) Getting ready for reading: early phoneme awareness and phonics teaching improves reading and spelling in inner-city second-language learners, British fournal of Educational Psychology, 69, 587-605.

Stuart, M. \& Coltheart, M. (1988) Does reading develop in a sequence of stages?, Cognition, 30, $139-181$.

Stuart, M., Masterson, J. \& Dixon, M. (2000) Spongelike acquisition of sight vocabulary in beginning readers?, fournal of Research in Reading, 23, 12-27.

Stuart, M., Masterson, J., Dixon, M. \& Quinlan, P. (1999) Inferring sublexical correspondences from sight vocabulary: evidence from 6- and 7-year olds, Quarterly fournal of Experimental Psychology, 52, 353-366.

Stuart, M., Doctor, E., Olisa, J. \& Dodds, P. (2003) The benefits of early phoneme awareness and phonics teaching, Dyslexia Review, 14, 9-13.

Thompson, G. B., Cottrell, D. S. \& Fletcher-Finn, C. M. (1996) Sublexical orthographic-phonological relations early in the acquisition of reading: the knowledge sources account, fournal of Experimental Child Psychology, 62, 190-222.

Torgesen, J. K., Morgan, S. \& Davis, C. (1992) The effects of two types of phonological awareness training on word learning in kindergarten children, fournal of Educational Psychology, 84, 364-370.

Treiman, R., Tincoff, R. \& Richmond-Welty, E. D. (1996) Letter names help children to connect print and speech, Developmental Psychology, 32, 505-514.

Treiman, R., Tincoff, R., Rodriguez, K., Mouzaki, A. \& Frances, D. J. (1998) The foundations of literacy: learning the sounds of letters. Child Development, 69, 1524-1540.

Tunmer, W. E., Herriman, M. L. \& Nesdale, A. B. (1988) Metalinguistic abilities and beginning reading. Reading Research Quarterly, 23, 134-158.

Uhry, J. K. \& Shepherd, M. J. (1993) Segmentation/spelling instruction as part of a first-grade reading program: effects on several measures of reading, Reading Research Quarterly, 28, 219-233. 